\title{
Morphological Aspects and Differences Between Segments of the Oviduct in Chicken
}

\author{
Cătălin TODIREANU ${ }^{1 *}$, Corneliu COTEA ${ }^{1}$, Carmen SOLCAN ${ }^{1}$ and Pieter CORNILLIE ${ }^{2}$ \\ ${ }^{1}$ Department of Preclinics, Faculty of Veterinary Medicine, University of Agricultural Sciences and \\ Veterinary Medicine, Iași, Romania \\ ${ }^{2}$ Department of Morphology, Faculty of Veterinary Medicine, UGent, Ghent, Belgium \\ *Corresponding author, e-mail: todireanu.catalin@gmail.com
}

Bulletin UASVM Veterinary Medicine 71(2) / 2014,

Print ISSN 1843-5270; Electronic ISSN 1843-5378

DOI:10.15835/buasvmcn-vm: 10502

\begin{abstract}
Although the gross morphology and structure of the oviduct is similar in the entire organ, there are morphological, structural, histochemical and ultrastructural differences between the segments, particular to their function.

The present study highlights the anatomical and structural differences between the five segments of the oviduct: infundibulum, magnum, isthmus, uterus and vagina.

A number of 30 Lohmann Brown chickens aged between 19 and 50 weeks were used for this research. Samples were taken from each segment and fixed in $4 \%$ buffered formalin and Bouin; embedded in paraffin, cut at $5 \mu \mathrm{m}$ and stained PAS, H-E, Novelli, Masson, Van Gieson and Von Kossa.

The infundibulum presents two areas that have a distinct morphology and structure. The funnel has very thin walls with small mucosa folds while the infundibular neck is thicker and presents small tubular glands in the lamina propria of the mucosa. Magnum has the largest mucosa folds that consist of tubular glands which elaborate the albumen. The morphology of the next segment, isthmus, is similar to that of the magnum, but the folds are lower and thinner. In this segment, the secretion takes a particular shape as filaments that form the shell membranes. The uterus is very well distinguished from the other segments based on its' morphology that has a sack shape. The mucosa folds are leaf-shaped and the musculosa is very well developed. The vagina has numerous thin and tall primary folds with secondary and tertiary folding, and the tubular glands from this segment are missing. The smooth muscular cells are grouped in bundles, surrounded by connective tissue.

We described numerous differences in the morphology, structure and histochemistry of the five oviduct segments in chicken.
\end{abstract}

Keywords: chicken, histology, histochemistry, oviduct

\section{INTRODUCTION}

The oviduct is a very sinuous, muscular organ, in shape of a long tube, unevenly calibrated, that occupies the dorsal area of the abdominal cavity in chickens. It is formed of five morphologically distinct segments: infundibulum, magnum, isthmus, uterus and vagina (Hodges, 1974; Cotea, 2013). Each of these segments presents the same basic structure, although, because of the different function of each segment, there are some anatomical and structural differences between them.

The overall histological structure of the oviduct consists of four tunics: mucosa, sub-mucosa, muscular and serous (Jamieson, 2007). The mucosa is structured of a pseudo-stratified epithelium with cilia and a lamina propria. The epithelium presents alternating secreting cells and prismatic cells with cilia (Chousalkar and Roberts, 2007). In the lamina propria there are tubular glands that secrete the egg components and open in the lumen of the epithelium (Khokhlov, 2008).

To increase the secretion surface of the epithelium the mucosa forms primary, secondary and tertiary folds (Todireanu et al., 2013).

The oviduct submucosa is structured from a thin layer of connective tissue with blood vessels 
that ensure the blood supply for the mucosa folds (Khokhlov, 2008).

The muscular tunic consists of two layers of smooth muscle cells oriented differently, forming an inner circular and an outer longitudinal layer (Kawashima et al, 1999).

On the outside, the oviduct is covered by the serous tunic which is a fasciculated mesothelium (Cotea, 2013).

The segments of the oviduct can be differentiated on anatomical criteria but using histology and cytochemistry we can highlight more details regarding the structural differences.

\section{MATERIALS AND METHODS}

The samples for this study were taken from 30 Lohmann Brown chickens aged between 19 and 50 weeks. The chickens were chosen from AlfaProd farm, Botosani, Romania, and from De Biest farm, Kruishoutem, Belgium. The Lohmann Brown crossbreed is the result of numerous progresses in the chicken genetics field.

To have complete results, we studied the morphology of the oviduct using different examinations: anatomical, histological and histochemical.

The anatomical exam highlighted the macroscopic differences between the segments and also their particularities. The length and width of each segment was measured in order to be compared with each other.

Using histology techniques we distinguished the differences in structure between the oviduct segments. For the histological and histochemical exams, the samples were fixed in $4 \%$ buffered

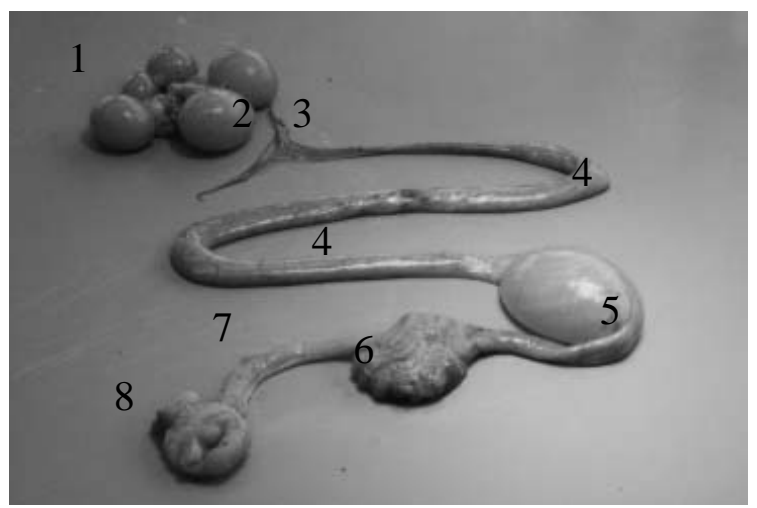

Fig. 1. Chicken oviduct: 1-ovary, 2-funnel, 3-neck of the infundibulum, 4-magnum, 5-isthmus (with egg mass), 6-uterus, 7-vagina, 8-cloaca formalin and Bouin; embedded in paraffin, cut at $5 \mu \mathrm{m}$ and stained PAS, H-E, Novelli, Masson, Van Gieson and Von Kossa. The images were examined under the B1-211A optic microscope equipped with Moticam 1000 video camera and Images Plus 2.0 software.

\section{RESULTS AND DISCUSSION}

The infundibulum is the first and cranial oriented segment of the oviduct, and is divided into two morphologically distinct areas: the funnel and the neck (Fig. 1). The anterior part of the infundibulum is opened, with a very thin wall and fringed edges that surround the ovary in order to capture the oocyte during the follicular dehiscence (Fig. 2). Toward the magnum, the walls of the funnel become thicker, converge and form the neck of the infundibulum (Fig. 1;2).

The funnel has a different histological structure than the rest of the oviduct. The mucosa presents the surface epithelium and lamina propria, but in the lamina propria the tubular glands are missing (Fig. 3). The muscular tunic is very well represented but the orientation of the fibres is different than in the other segments. The difference is that in this segment we noticed that the smooth muscle cells are gathered in groups that have different orientation, while in most of the oviduct these cells are arranged into two layers (Fig. 4). These small groups of smooth muscle tissue give the funnel the necessary mobility to fold on the ovary during the follicular dehiscence and capture the oocyte.

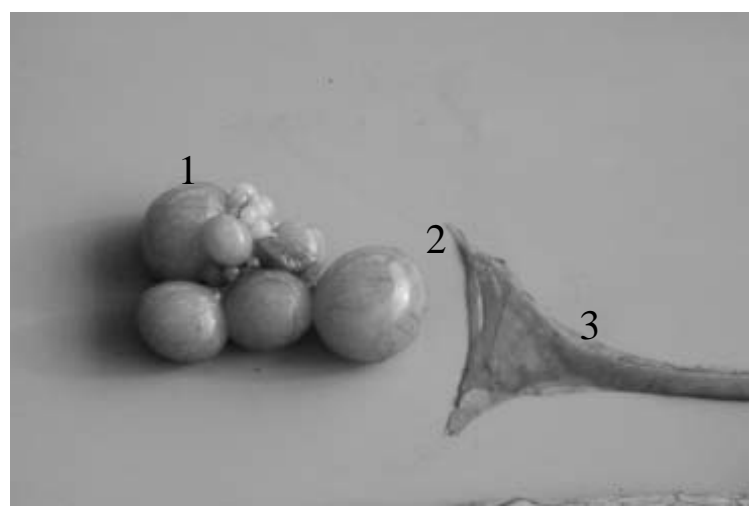

Fig. 2. Chicken infundibulum: 1- ovary, 2-funnel, 3-neck of the infundibulum 
The muscular tunic is covered on the outside by the serous tunic which is a fasciculated mesothelium(Fig. 4).

In the epithelium of the funnel there are numerous prismatic cells with cilia, while the secreting cells are very few, proving that this segment is involved more in the capture of the oocyte rather that in secreting egg components (Fig. 5).

The neck of the infundibulum presents a mucosa with high and thin folds that have numerous secondary and tertiary folding (Fig. 6).

The epithelium consists of secreting cells and prismatic cells with cilia, the first predominating. The secreting cells are loaded with secreted mate-

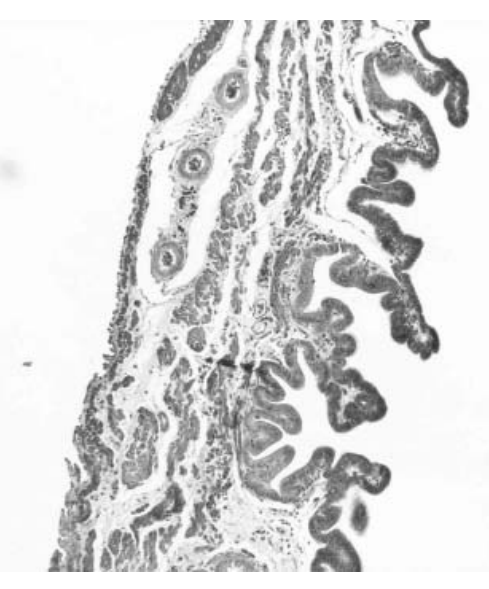

Fig. 3. Infundibulum funnel presents small folds of mucosa that has a pseudostratified epithelium and is lacking the tubular glands in the lamina propria. Masson stain, $\mathrm{x} 40$

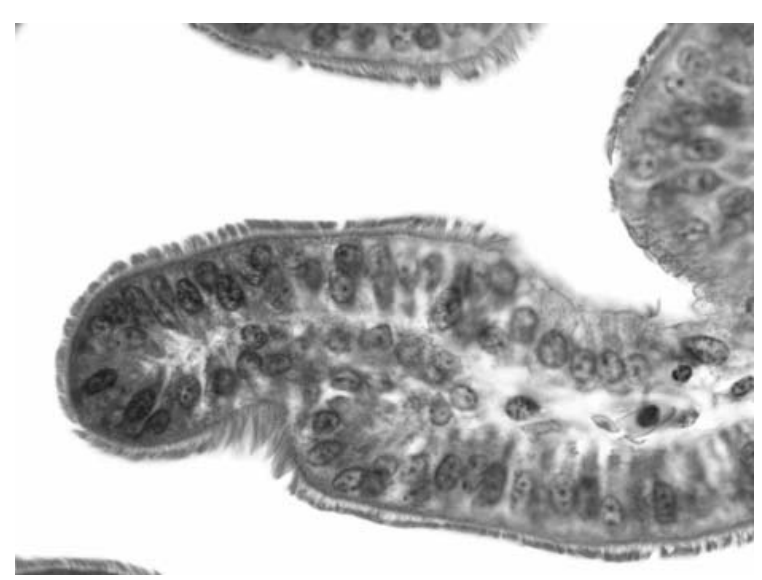

Fig. 5. Infundibulum funnel with numerous prismatic cells with cilia and very few secreting cells. Masson stain, x600 rial that gathers at the apical pole, pushing the nucleus in the basal third of the cell (Fig. 7). In the lamina propria there are few and small tubular glands with secreting cells (Fig. 8). These cells both from the lamina propria and the goblet cells from the epithelium secrete the chalazae and a thin layer of albumen. This is the reason why there are some many secondary and tertiary folding, because the lamina propria glands are not very well developed and a large number of epithelial goblet cells is required.

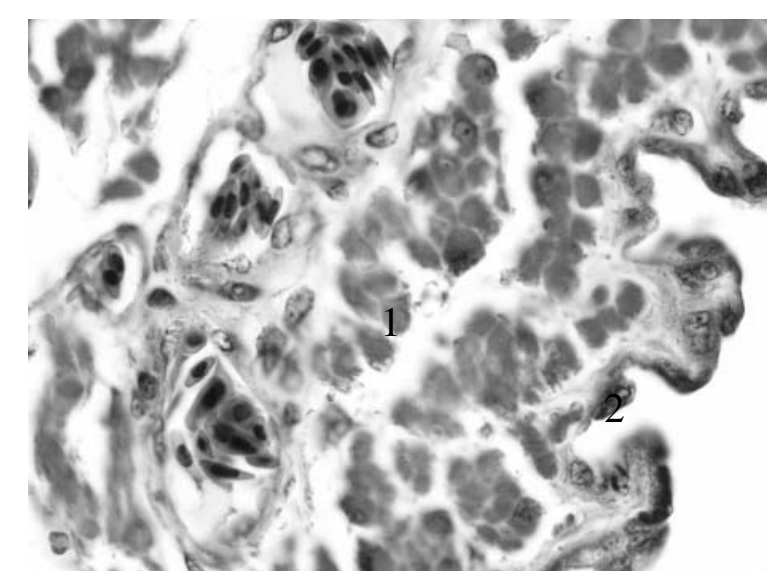

Fig. 4. Infundibulum funnel. The very well developed muscular tunic that consists of smooth muscle cells arranged in groups (1), and also the serous tunic on the outside (2). Masson stain, x1000

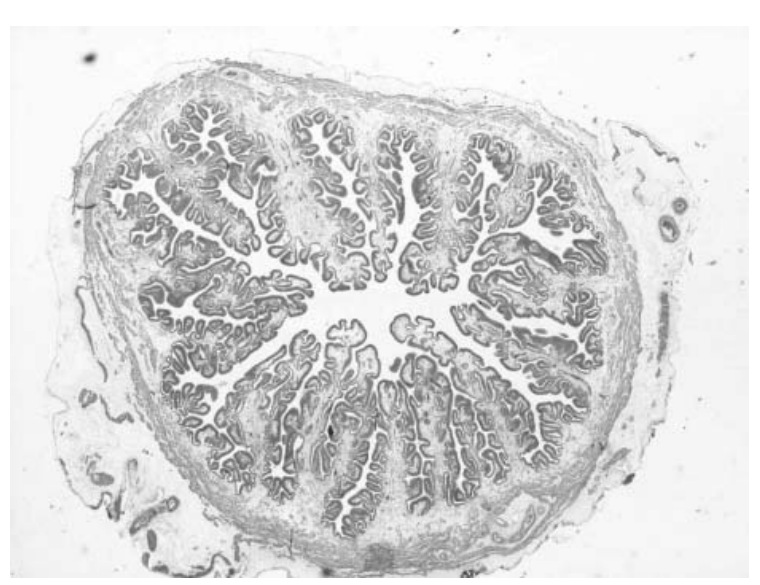

Fig. 6. Infundibulum neck with primary, secondary and teriary folds. Masson stain, $\mathrm{x} 40$ 
The muscular tunic resembles the rest of the oviduct, being structured of two layers of smooth muscle tissue oriented circular and longitudinal (Fig. 9).

The average length of the infundibulum is 16 $\mathrm{cm}$ and the diameter is $7 \mathrm{~mm}$.

The second segment of the oviduct is magnum, which is the most developed, with an average length of $46 \mathrm{~cm}$ and a diameter of $17 \mathrm{~mm}$. It is so highly developed because it has to secrete almost the entire albumen during the oocyte passage through it that takes only 3 hours (Fig. 10).

To elaborate this much albumen in this time, the tubular glands in the lamina propria are very

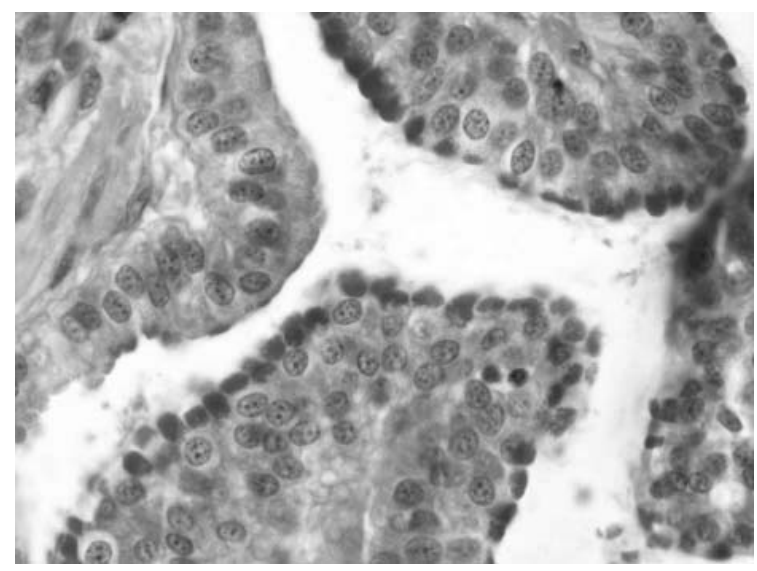

Fig. 7. Infundibulum neck. The epithelium presents numerous secreting cells with PASpositive secretion at the apical pole. PAS stain, $\mathrm{x} 1000$
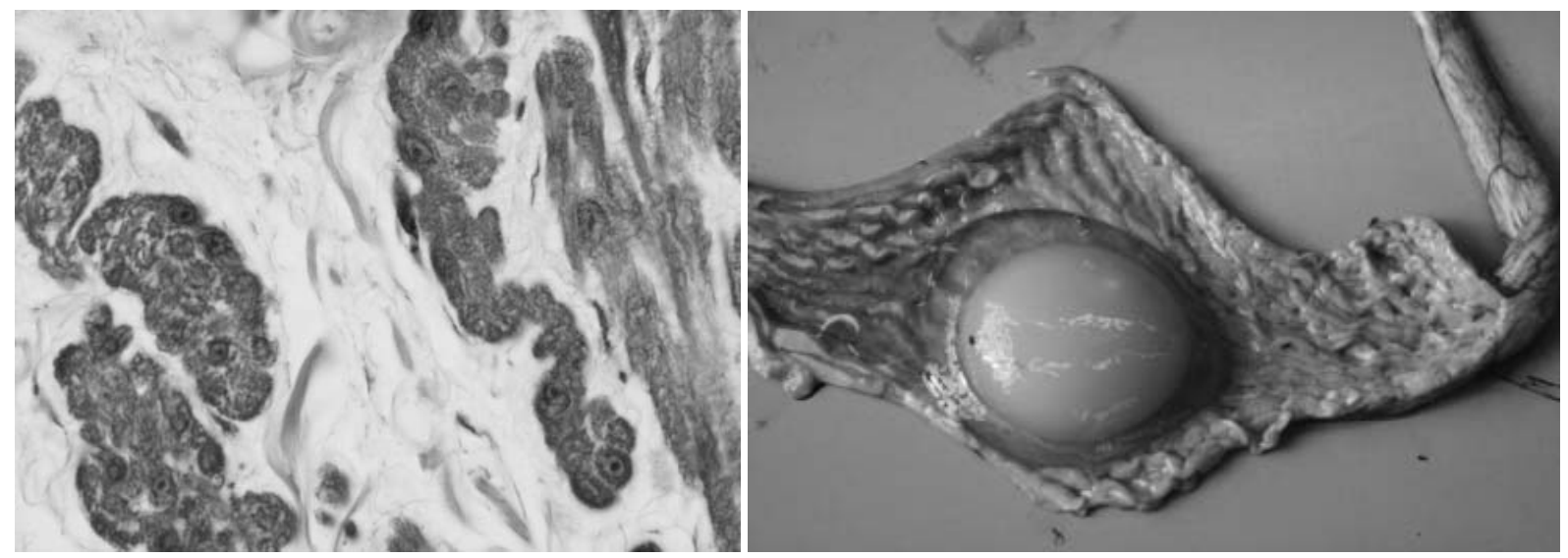

well developed making the folds very large and high (Fig. 11). There few secondary folds and very few tertiary because the main secreting activity takes place in the tubular glands from the lamina propria, so this segment presents very well developed primary folds (Fig. 11). In the epithelium of the mucosa there are both secreting goblet cells and prismatic cells with cilia, in an approximate 1:1 ratio. The muscular tunic has the same structure, but it is more developed in this segment than the infundibulum.

The isthmus is clearly separated from the magnum by a narrow, translucent area made of connective tissue (Fig. 13). This segment has an

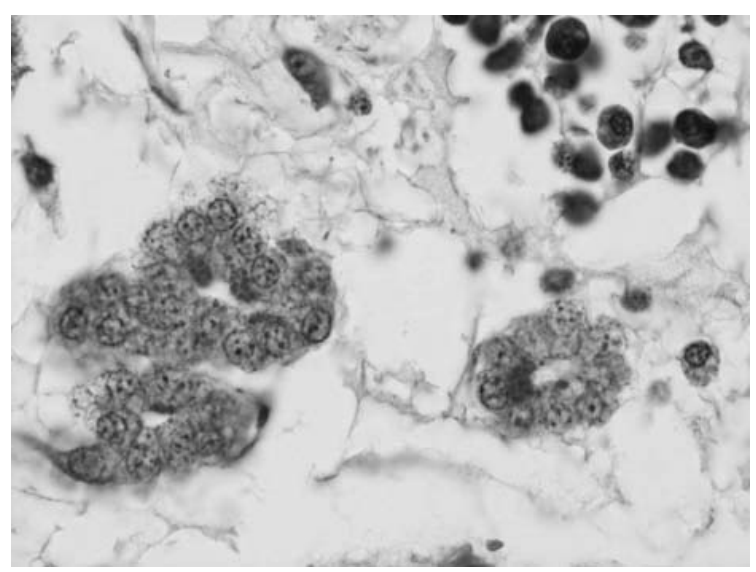

Fig. 8. Infundibulum neck. Tubular glands in the lamina propria of the mucosa. Masson stain, x1000

Fig. 10.The aspect of the egg mass formation in the magnum. The morphology of the magnum mucosa folds
Fig. 9. Infundibulum neck. The muscular tunic with the two layers of smooth muscle cells: inner circular and outer longitudinal. Masson stain, x600 


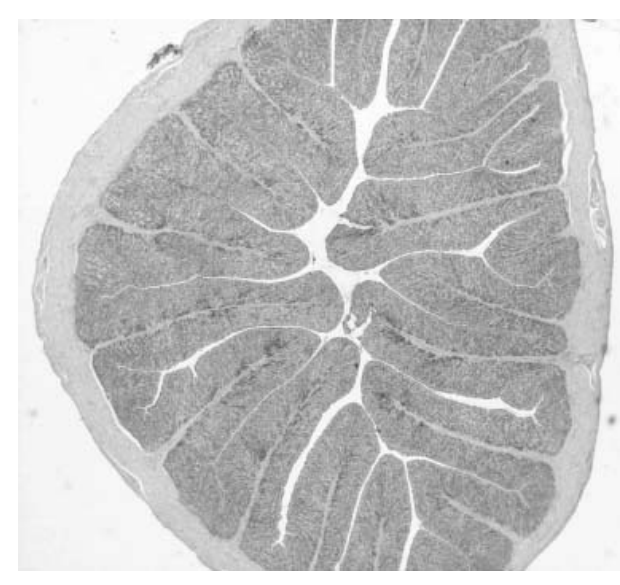

Fig. 11. Magnum with very well developed primary folds on behalf of the tubular glands in the lamina propria. There are few secondary foldings. PAS stain, $\mathrm{x} 20$

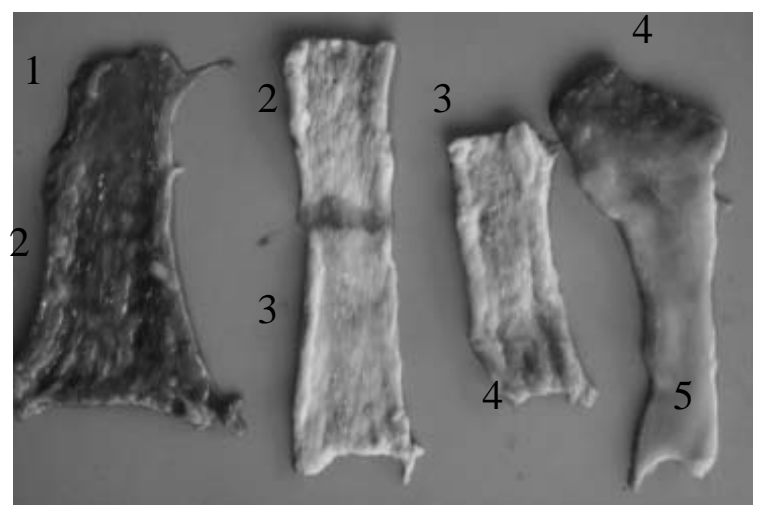

Fig. 13. The different morphological aspects of the oviductal segments mucosa: infundibulum neck (1), magnum (2), isthmus (3), uterus (4), vagina (5)

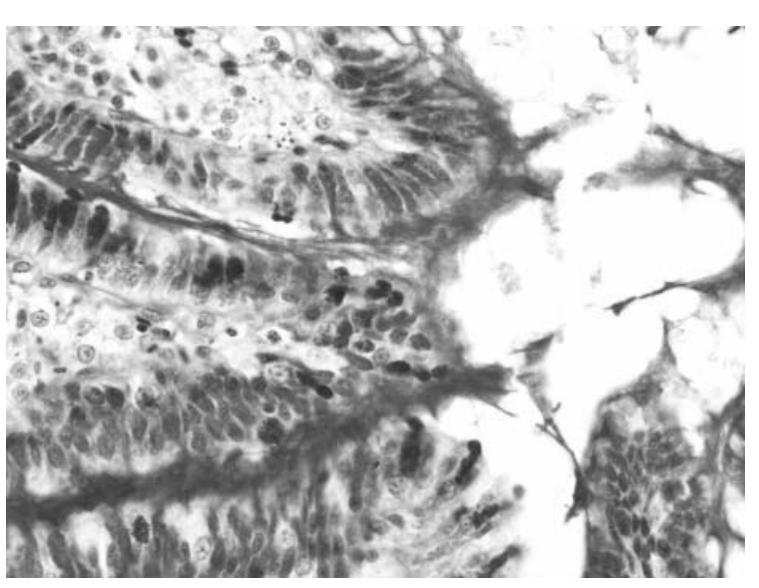

Fig. 15. Isthmus with the secreted material that takes the shape of rows or filaments.

PAS stain, $\mathrm{x} 800$

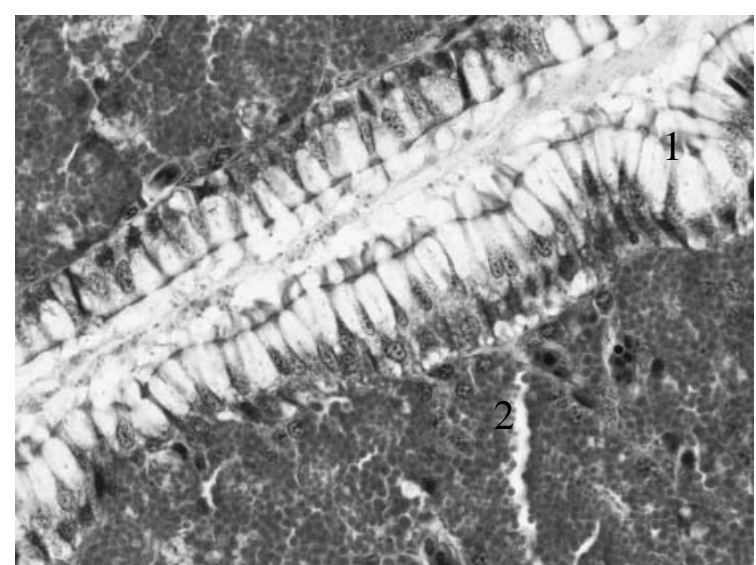

Fig. 12. The epithelium with goblet cells and prismatic cells with cilia (1). The lamina propria with tubular glands filled with albumen secretion granules (2). Masson stain, x1000

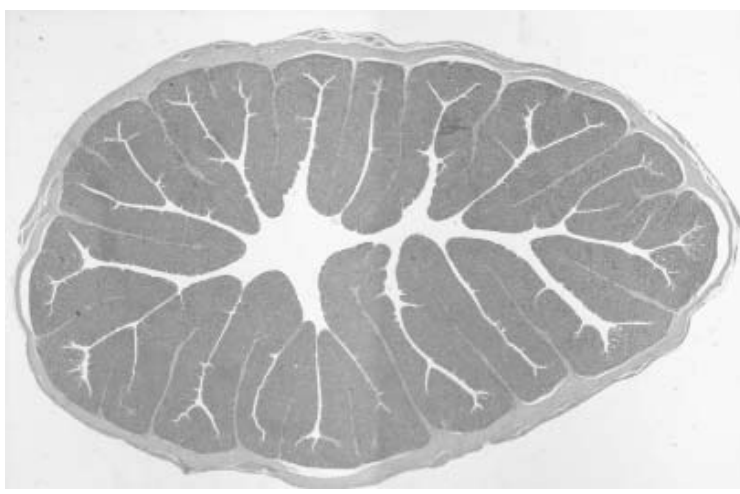

Fig. 14. Isthmus with well developed primary folds on behalf of the tubular glands. There are few secondary and tertiary foldings. PAS stain, $\mathrm{x} 20$

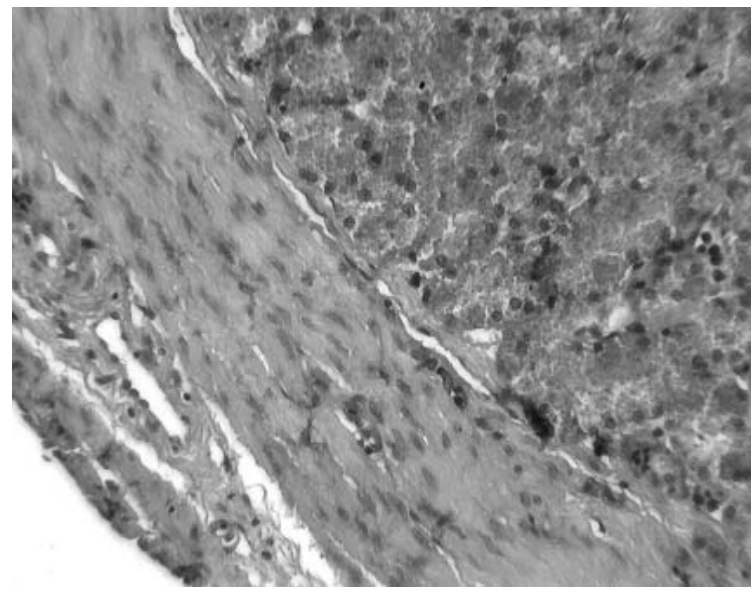

Fig. 16. Isthmus with well developed muscular tunic, especially the inner circular layer of smooth muscle cells.van Gieson stain, x400 


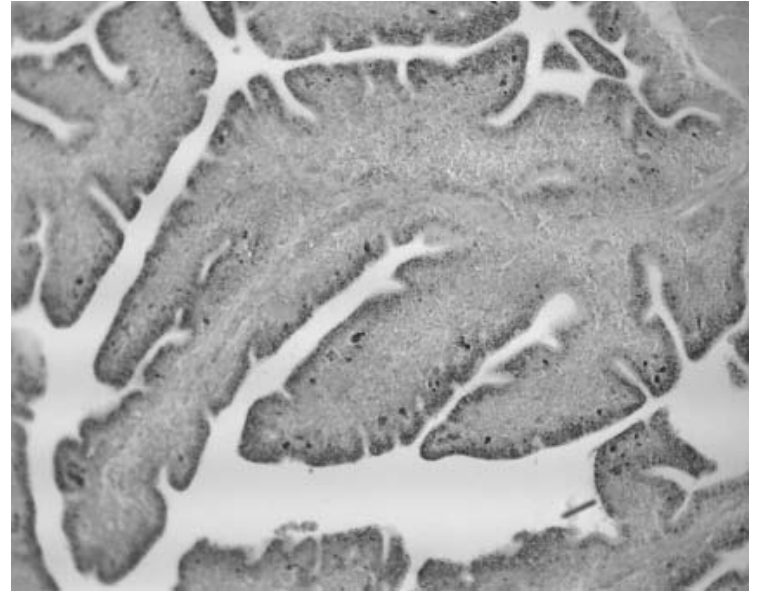

Fig. 17. Uterus with mineralisation sites in the epthelium and smaller folds.van Kossa stain, x400

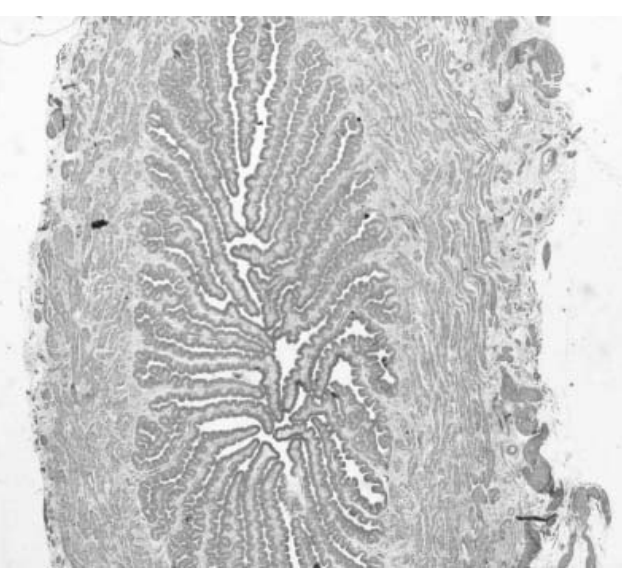

Fig. 19. Vagina with numerous primary, secondary and tertiary folds with the role of expanding the secretion surface. Masson stain, $\mathrm{x} 200$

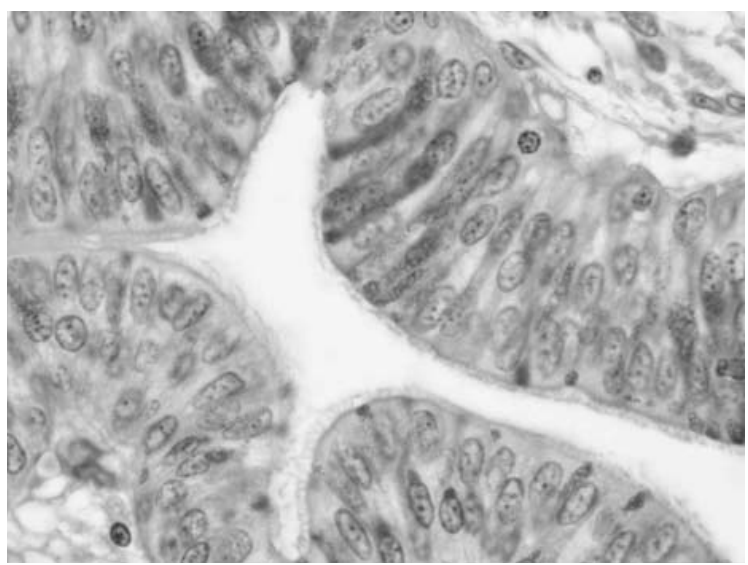

Fig. 21. Vagina with rare secreting goblet cells at the base of the epithelial folds.

PAS stain, x800

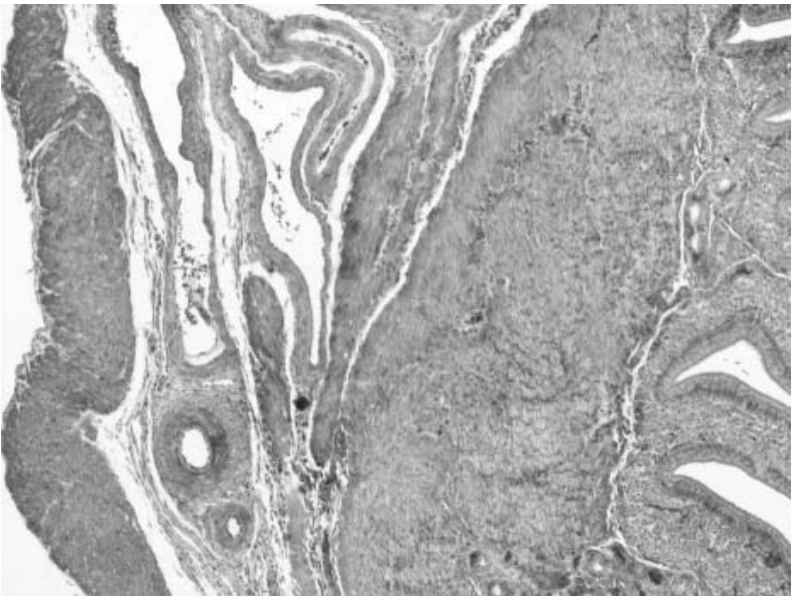

Fig. 18. Uterus with very well developed muscular tunic, especially the inner circular layer of smooth muscle tissue. Masson stain, x200

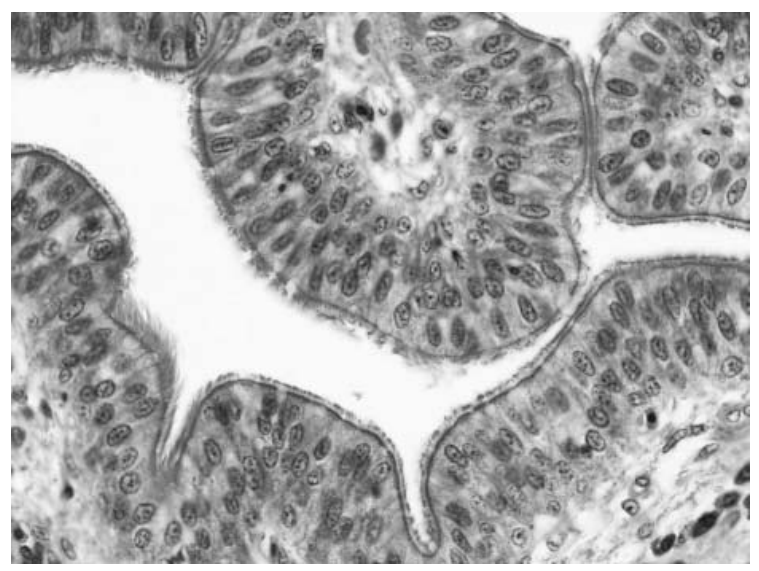

Fig. 20. Vagina with numerous prismatic cells with cilia in the epithelium of the mucosa tunic. Masson stain, $\mathrm{x} 600$

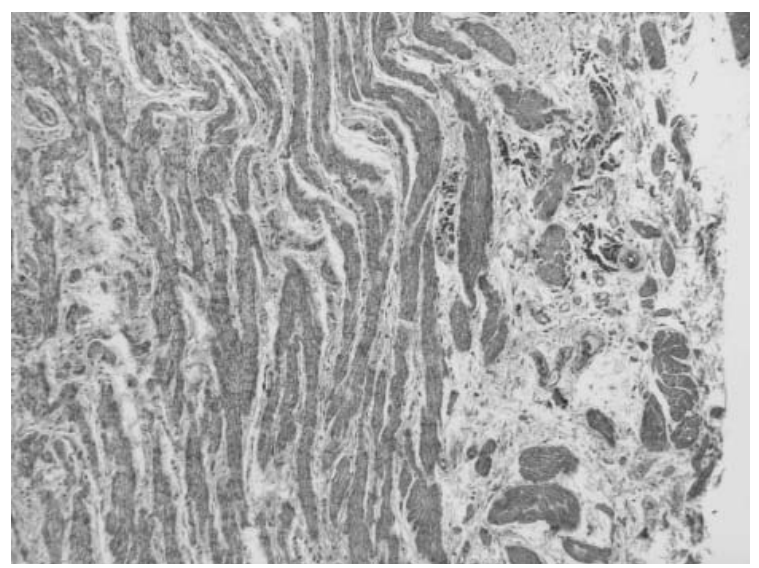

Fig. 22. Vagina with a very well developed muscular tunic, especially the inner circular layer of smooth muscle tissue that is arranged in bundles. Masson stain, $\mathrm{x} 200$ 
average length of $12 \mathrm{~cm}$ and a diameter of $10 \mathrm{~mm}$. Its' morphology and structure is similar to that of the magnum, but the tubular glands are not so well developed in the lamina propria. Because of this, the folds are smaller both in height and width, and present more secondary and tertiary folding (Fig. 14).

The isthmus epithelium also presents alternating secreting and prismatic cells that are in the same 1:1 ratio on most of the folds' surface but at the basis of the folds the secreting goblet cells are more frequent. The secreted material is PAS-positive and has a particular aspect in this segment being shaped as rows or filaments in the lumen (Fig. 15). This material will structure the shell membranes. The muscular tunic is more developed in this segment than in the magnum, especially the inner circular layer of smooth muscle cells (Fig. 16).

The anatomy of the uterus is different from that of the other segments because it is shaped as a sack, while the other segments are tubular. This shape allows it to keep the egg in this segment and rotate it for about 19 hours, while the shell is elaborated. Because it has to keep the egg for a longer period of time and also to rotate it, the muscular tunic is more developed in this segment than in those before where the egg just passed through in spiral movement. The mucosa folds are lower, leaf-shaped, with fewer tubular glands and present more secondary and tertiary folds than in the magnum or isthmus (Fig. 17). This aspect proves the involvement of the epithelium goblet cells in egg shell secretion because the development of secondary and tertiary folding detrimental to tubular glands indicates a necessity for more secreting cells in the epithelium. Using von Kossa stain the mineralization process in the uterus is highlighted, being positive in the secreting goblet cells from the epithelium (Fig. 17).

The muscular tunic is very well developed and the inner circular layer is better represented than the outer longitudinal. Between these two layers of smooth muscle tissue there are large blood vessels (Fig. 18).

The last segment of the oviduct is the vagina, with a length of $14 \mathrm{~cm}$ and a diameter of $8.5 \mathrm{~mm}$. It is a very twisted muscular duct, soldered to the uterus by rich connective tissue. The main purpose of the vagina is egg expulsion. Also, in this segment the cuticle that covers the egg is elaborated and sperm is stored. To achieve these functions the vagina presents a different morphology. The mucosa of this segment lacks tubular glands in most of the lamina propria which proves that the cuticle is secreted by the goblet cells in the epithelium. In order to enlarge the secretion surface the mucosa forms numerous primary, secondary and tertiary folds that are high and thin (Fig. 19). In some areas of the vagina, tubular glands can be found, having the role of nourishing the sperm cells. The epithelium consists of numerous prismatic cells with cilia (fig. 20) and fewer secretion goblet cells with PAS-positive granules at the apical pole (Fig. 21). The goblet cells can be found frequently at the base of the folds while the prismatic cells dominate the rest of the mucosa folds (Fig. 20; 21).

This segment has a very well developed muscular tunic with a larger inner circular layer. The smooth muscle tissue organises in bundles surrounded by connective tissue and blood vessels (Fig. 22). This allows it to flex and perform different movements in order for the egg to be expelled.

\section{CONCLUSIONS}

Although it would seem that the oviduct in chicken presents the same morphology there are numerous differences between the five segments, according to their function. These differences are at least anatomical, histological, cytochemical and functional and were highlighted in the present research.

Each of the segments has a morphology particular to its role in egg formation and it developed in order to elaborate the egg mass in less time. These segments are highly developed in the Lohmann Brown crossbreed, this being the reason for which this breed of chickens has been chosen for the study.

Acknowledgement: This paper was published under the frame of European Social Fund, Human Resources Development Operational Programme 2007-2013,projectno. POSDRU/159/1.5/S/132765.

\section{REFERENCES}

1. Chousalkar K, Roberts J (2007). Ultrastructural changes in the oviduct of the laying hen during the laying cycle. Cell Tissue Res. vol. 332, p. 349-358.

2. Cotea, C (2013). Histologie specială. Ed. Tehnopress, Iasi. 
3. Hodges RD (1974) The histology of the fowl. Ed. Academic Press, London.

4. Jamieson B (2007). Reproductive Biology and Phylogeny Series. Ed. Science Publishers.

5. Kawashima M, Takahashi T, Kondo S, Yasuota T, Ogawa $\mathrm{H}$ Tanaka K (1999). Identification of an androgen receptor within the uterus of the domestic fowl. Poultry Science, vol. 78, p. 680-689.
6. Khokhlov RY (2008). Morphology of an infundibulum of the oviduct of sexually mature hens. Int. J. Morphol., p. 883-886.

7. Todireanu C, Cotea C, Solcan C, Cornillie P (2013). New insights into the morphology and fine structure of the chicken vagina. Lucr. șt. Med. Vet. Iasi. vol. 56, p. 104-109. 